\title{
Refletindo a construção da docência baseada numa justiça curricular
}

\author{
Rodrigo Furtado Costa
}

Cientista Social pela Faculdade de Ciências e Letras - campus de Araraquara da Universidade Estadual Paulista Júlio de Mesquita Filho (FCL/UNESP/CAr); especialista em Gestão e Exercício da Docência no Ensino Superior pela Faculdade do Noroeste de Minas (FINOM/Paracatu). Professor das áreas de Ciências Sociais e Educação da Faculdade Frutal (FAF) e da Universidade do Estado de Minas Gerais (UEMG), unidade de Frutal.

prof_rodrigo_sociologia@yahoo.com.br rodrigofurtado@sociologist.com.

\section{Resumo}

Diante de um complexo processo de ressignifcação de valores, ideias e atitudes no que se referem às relações pessoais e culturais, num mundo em que a ideia de globalização do capital e da produção determinam novas posturas e maneiras de ser, pensar e agir, propomos uma discussão sobre a construção da docência e dos currículos escolares como instâncias que refletem esse processo de quebra de paradigmas. Buscamos confirmar a centralidade da cultura na construção de uma educação emancipatória calcada no respeito e na convivência com a alteridade, de modo que possamos refletir acerca da educação e da escola que queremos, numa sociedade em que os valores de justiça e autonomia de pensamento andam profundamente relativizados.

Palavras-chave: cultura; educação; emancipação; currículo escolar. 
"Mestre não é quem sempre ensina, mas quem de repente aprende" Guimarães Rosa, Grande sertão: veredas

A educação contemporânea exige continuadamente uma releitura crítica diante dos impasses e perspectivas de suas políticas atuais. Essas sequer podem ser concebidas separadas de alguns pressupostos filosóficos, históricosociais, econômicos e culturais que sustentam sua aplicação, principalmente num momento de explícito movimento dialético observado no interior da transição de paradigmas da sociedade mundial que, por sua vez, se faz sentir também nos currículos escolares e na prática curricular!'

O objetivo desta discussão é fazer alguns apontamentos sobre esses impasses e perspectivas, de modo que possamos lançar alguma luz sobre o debate vigente acerca da construção de caminhos que atentem para a importância do multiculturalismo ${ }^{2}$ na elaboração dos currículos escolares. Procuraremos, nesse sentido, debater a hipótese de que o currículo escolar e a prática curricular podem ser caminho seguro para que a escola confirme seu papel de agente transformador e emancipador, desde que os atores sociais atuantes nesse espaço institucional, sobretudo os docentes, compreendam minimamente a construção de alguns possíveis significados de multiculturalismo.

\footnotetext{
I Diante do turbilhão de transformações culturais e de ressignificação de valores pelas quais passa a sociedade mundial economicamente globalizada, à escola se coloca também a necessidade de efetivas e profundas mudanças no exercício de suas práticas e culturas para conseguir enfrentar muitos dos desafios do mundo atual. Nesse sentido, segundo Pimenta e Anastasiou (2002), "as rápidas transformações do mundo do trabalho, o avanço tecnológico configurando a sociedade virtual e os meios de informação e comunicação" e, consequentemente, uma maior aproximação no âmbito das relações culturais, pessoais e étnicas - típicas do ambiente global predominante na atual história do capitalismo - acabam por incidir "fortemente na escola, aumentando os desafios para torná-la uma conquista democrática efetiva” (p.I2). Ora, tem-se aí claramente o desafio de se dar conta dos novos impasses que se impõem à prática docente e aos currículos escolares no âmbito da necessária transição de velhos para novos paradigmas: "transformar práticas e culturas tradicionais e burocráticas das escolas [e] educar as crianças e jovens, propiciando-lhes um desenvolvimento humano, cultural, científico e tecnológico, de modo que adquiram condições para enfrentar as exigências do mundo contemporâneo" (ibid., p. I2).

${ }^{2}$ A concepção de multiculturalismo teve início na década de 1970 quando o Canadá fez dela, pela primeira vez, uma política oficial. Pouco depois, tal concepção tornou-se o grande conceito em voga no mundo, sobressaindo-se na União Europeia e tendo o Reino Unido em sua vanguarda. Sua base teórica diz respeito à integração de culturas, de modo que se entenda - no decurso histórico da construção de seus significados e ressignificados - questões como "liberdade cultural" e "celebração de todas as formas de herança cultural”. Atualmente, porém, há uma dúvida pairando sobre o entendimento dessas categorias, segundo o economista ganhador do Prêmio Nobel de Economia em 1989, Amartya Sen (2006), que afirma que essa dúvida se inicia em "um raciocínio incorreto [de modo que] não se deve confundir, de um lado, a liberdade cultural - elemento fundamental da dignidade de todos os povos - e, de outro, a defesa de celebração de todas as formas de legado cultural, sem procurar saber se os indivíduos envolvidos escolheriam essas práticas de fato se tivessem a possibilidade de fazer um exame crítico delas". $O$ economista mostra que a liberdade cultural, "bem compreendida, consiste em saber resistir à aprovação sistemática das tradições passadas, quando os indivíduos veem razões para mudar seu modo de vida” (p. 3). Diante disso, muitas nações acabam isolando - através da noção do que é multicultural - os indivíduos em comunidades. Nesse sentido, quando um povo e/ou comunidade social e etnicamente configurados conseguem achar razões para mudar seu modo de vida, entender que políticas oficiais devam impedir tal mudança em nome de uma tradição é, minimamente, uma forma muito pouco multicultural. Há, então, uma confusão em detrimento à integração multicultural. O resultado é que países como Dinamarca, Reino Unido, Holanda, França, sob o manto da dúvida ou do ceticismo, estão pensando ou já reverteram suas políticas públicas. Sobre essa temática, ver SEN, Amartya. Identy and violence. W.W Norton, 2006.
} 


\section{Educação para a emancipação: uma reflexão a partir da história}

A concepção de educação emancipatória ${ }^{3}$ teve com o filósofo alemão Theodor Adorno (1906-1969) fundamental contribuição. Entre as duas grandes guerras mundiais - especificamente nas décadas de 1920 e 1930 -, tivemos o surgimento dos regimes totalitários nazista (Alemanha) e fascista (Itália), cuja influência se fez sentir em outras áreas da Europa (Espanha, Portugal), da Ásia (Japão) e da própria América do Sul (Brasil, com a ditadura do Estado Novo de Getúlio Vargas), fatos esses testemunhados pelo pensador e que nos legaram uma história sombria de etnocídio e holocausto. Segundo Adorno:

a exigência que Auschwitz não se repita é a primeira de todas para a educação. [...] Se as pessoas não fossem profundamente indiferentes em relação ao que acontece com todas as outras, excetuando o punhado com que mantêm vínculos estreitos e possivelmente por intermédio de alguns interesses concretos, então Auschwitz não teria sido possível, as pessoas não o teriam aceito (ADORNO, 1995, p.119, 134).

Diante desse quadro histórico totalitário de opressão e barbárie em face de princípios essenciais dos direitos humanos, Adorno e outros filósofos associados à escola de pensamento frankfurtiano realizaram formulações teóricas e postulados éticos que representaram importante expressão científica, proporcionando, assim, contribuições significativas para o entendimento e a crítica das questões educacionais contemporâneas. Seus estudos permitem desvendar vários aspectos das contradições presentes no cientificismo e no racionalismo instrumental típicos de nossa sociedade historicamente classificada como moderna e marcada pelo sofrimento, pela barbárie e pelo processo de "coisificação" do ser humano, possibilitando, como resultado, pensar em uma educação para a emancipação.

De acordo com as filósofas Aranha e Pires, na esteira da melhor tradição frankfurtiana:

Theodor Adorno integrou o grupo que formulou a filosofia do Instituto de Pesquisa Social, de Frankfurt, também conhecida como Teoria Crítica. Seus mentores se recusaram a aceitar a premissa de que aderir à Razão é algo "inocente", de modo que a concepção iluminista de que o logos é efetivado por meio da

\footnotetext{
${ }^{3}$ A ideia de emancipação, aqui, realiza-se a partir do entendimento da educação como espaço de formação que possibilite a construção e exercício da autoconsciência e da crítica, do pensar e refletir para compreender o mundo e desvendar as ideologias presentes nas produções e práticas realizadas pelos indivíduos.
} 
ciência sofreu crítica ardorosa por parte de pensadores de garbo como Horkheimer, W. Benjamin, Marcuse e Habermas (ARANHA; PIRES, 1993, p. 124).

Nesse sentido, as críticas feitas pelos frankfurtianos à crença na ciência e na técnica como "redentoras" da liberdade:

repudiaram-nas como instrumentos de emancipação social, uma vez que o progresso custa a execração do "sujeito autônomo", ou seja, custa a sua anulação, sujeito este que passa a ser cooptado pela indústria cultural ou pela sociedade unidimensional. $O$ resultado é que as práticas humanas em suas diversas manifestações (econômica, social, política, cultural, estética e ética) são arbitrariamente uniformizadas (ibid., p. 124).

E prosseguem:

tal fato leva, portanto, ao exercício de uma forma de racionalidade chamada razão instrumental, ou seja, é a prática de uma racionalidade científica "de cunho positivista" cujo objetivo é a dominação da natureza procurando atingir fins lucrativos. Nesse sentido, ciência e técnica ficam subordinados ao capital (ibid., p. 124).

Por tudo isso, Adorno, bem como os demais frankfurtianos, alertou-nos para a necessidade de se recuperar o indivíduo autônomo e consciente de seus objetivos, procurando buscar sua emancipação no âmbito individual através da autonomia da razão.

Ora, o fato histórico que nos apresentou exemplarmente essa "irracionalidade" revestida de modelos teóricos que "quiseram ser racionais" foi a barbárie do nazifascismo nos idos de 1920, 1930 e 1940. Adorno apontou a educação como forma de reflexão acerca dessa instrumentalização da sociedade que, mais tarde e no âmbito do capitalismo pós-guerra, reforçou o processo de reificação humana - que já se fazia sentir desde a Revolução Industrial oitocentista - com especial aguçamento da "mais-valia" relativa ${ }^{4}$, sobretudo em tempos de mundialização econômica.

Para o filósofo, a educação deve se voltar para a conscientização e posterior emancipação do sujeito. $O$ caminho para tal seria a reflexão que conduziria, por sua vez, à transformação. Nesse sentido, a educação deve, simultaneamente, evitar a barbárie (nazifascista) e buscar a emancipação

\footnotetext{
${ }^{4}$ Nesse sentido, entendemos o conceito de mais-valia relativa no âmbito do materialismo histórico e dialético configurado na obra do filósofo alemão Karl Marx.
} 
humana de modo que se questione a ideia de totalitarismo e, por extensão, a de educação autoritária. Portanto, o objetivo desse processo é pensar a educação emancipatória. Uma forma é apresentar um extenso projeto de transformação social global em que haja uma compreensão da totalidade da sociedade repressiva, de maneira que nele não ocorra o isolamento do processo educacional, refletindo, assim, seu papel transformador.

Não obstante, se levarmos em conta o caminhar do capitalismo após a Segunda Guerra Mundial, sob a análise de Adorno, não poderíamos duvidar de que todo esse esforço educativo estaria já em seu momento inicial condenado ao insucesso? E, por conseguinte: a educação poderia, então, manter algum fio de esperança se se pretende emancipatória?

Ora, observemos que as questões levantadas pelos frankfurtianos em geral e por Adorno, em particular, mostram-se claramente integradas com a problemática educacional contemporânea. A cultura escolar vigente - herdeira das características da escola moderna - pauta-se na visão monocultural que, por sua vez, institucionalizou-se. Nesse sentido, em tempos de educação ainda dual, de certa forma tida como uma mercadoria, a necessidade de buscarmos uma reinvenção da escola como espaço de cruzamento de culturas várias se faz urgente. Assim, é preciso buscar novos objetivos e estratégias na elaboração de currículos e na sua aplicação concreta, de maneira que se promova a articulação com as necessidades e perspectivas dos grupos excluídos social e culturalmente da escola e da sociedade do consumo.

O caminho para tal empresa é, em essência, o mesmo discutido por Adorno. Daí sua vívida atualidade: buscar um novo olhar que nos conduza à transformação e à emancipação. Noutras palavras, a necessidade de termos clara a importância da reflexão filosófica do nosso papel na sociedade e, por extensão - no tocante à educação - refletir acerca da função da escola: assumir nosso compromisso como educadores com postura, rigor, desvendando (no âmbito da relação ensino-aprendizagem) os mecanismos que impedem o ser humano de ser livre, enfim, de se emancipar.

Por tudo isso, é notória a necessidade - dentro da educação - da problematização das práticas escolares, do currículo, da relação entre as diversas culturas e do olhar sobre a alteridade, permitindo assim uma ação racional autônoma - cujos fins específicos sejam pensados claramente - acerca da condição humana e da busca de uma justiça curricular, segundo a herança do pensamento frankfurtiano. 


\section{Multiculturalismo e práticas educacionais: o desafio da educação emancipatória}

A história nos mostra que a ideia de educação reflexiva esbarra em impasses encontrados nos próprios currículos escolares e na própria prática docente. Estes não conseguem responder às demandas emancipatórias e mais humanizadoras que se tornam claras numa sociedade atual pautada na cultura urbana, consumista e massificada que acaba, por sua vez, reforçando o individualismo e reduzindo o sentido da vida ao gesto de comprar e consumir, competir e vencer. Assim impera uma visão fragmentada, alienada e ahistórica que leva à despolitização.

Diante disso, a contribuição de análises sobre a escola como espaço de "cruzamento de culturas" é indiscutível. Esses estudos mostram que o processo de elaboração dos currículos escolares e da prática curricular propriamente dita é caminho para se pensar a diminuição cultural da desigualdade inerente a grupos sociais que, por grande período, ficaram fora da escola, especialmente no Brasil. Segundo Moreira e Candau, "os novos desafios encontrados em sala de aula em face desses variados grupos sociais que passaram a compor o ambiente escolar, antes dele excluídos, não estão conseguindo responder aos problemas de como fazer com que a cultura seja questão central da elaboração curricular", bem como de "designar às práticas curriculares uma dimensão multicultural de maneira a incluir essa camada populacional respeitando seus interesses e perspectivas emancipatórias" (MOREIRA; CANDAU, 2003, p. I 56).

Nesse sentido, os autores procuram mostrar "a necessidade de formar o docente pautado no princípio da justiça curricular, cujo interesse é compreender que as práticas pedagógicas devem estimular o questionamento das relações de poder, contribuindo assim para a redução - dentro de um contexto democrático - da opressão, da discriminação e do preconceito" (ibid., p. 157). Para tanto, apresentam como objetivo discutir sugestões e princípios apresentados ao professorado - para além das cátedras - no esforço de colocar a cultura como condição sine qua non de suas práticas educacionais cotidianas. $E$ vão além:

tal perspectiva exige que desenvolvamos um novo olhar, uma nova postura, e que sejamos capazes de identificar as diferentes culturas que se entrelaçam no universo escolar, bem como de reinventar a escola, reconhecendo o que a especifica, identifica e distingue de outros espaços de socialização: a "mediação reflexiva" que realiza sobre as interações e o impacto que as 
diferentes culturas exercem continuamente em seu universo e seus atores (MOREIRA e CANDAU, 2003, p. I6I).

Inquestionável, portanto, é a centralidade da cultura na sociedade e na educação. Essa centralidade vem constantemente sendo ratificada pelos diversos autores e de diferentes matrizes teóricas, uma vez que no cenário contemporâneo "a cultura exerce papel constitutivo em todos os aspectos da vida social, posto que estamos diante de uma revolução cultural” (HALL, 1997, apud MOREIRA; CANDAU, 2003, p. I58). Faz-se necessário atentarmos para o papel do multiculturalismo como caminho norteador dos currículos escolares, enfim, da necessidade de termos essa consciência: é porque esse inevitável "caráter plural das sociedades atuais não está conseguindo responder aos dilemas e demandas provocados pela globalização econômica e pela mundialização da cultura" (ORTIZ, 1994, apud MOREIRA; CANDAU, 2003, p. I 56). Se essa empreitada obtiver sucesso, poderemos construir um caminho minimamente seguro para enxergar e debater a existência de perspectivas e de pontos de vista de minorias étnicas e raciais não incluídas socialmente, bem como de parcela da população constituinte das camadas populares.

Outro ponto importante são as relações entre escola e culturas. Elas apresentam a imperatividade da compreensão de que todo e qualquer processo educativo é fruto dessa mesma relação, uma vez que a escola se realiza socialmente como instituição cultural e que, por isso, deva ser capaz de fomentar suas práticas educativas para além dos obstáculos desafiadores que ora se apresentam no âmbito da nova ordem mundial: o mundo globalizado neoliberal.

Tais desafios exigem urgentes reflexões filosóficas, de modo que os educadores assumam o seu "compromisso como educador" com rigor. Dessa forma, é imperativo "(re)aprender" a ver o mundo, sob a égide de um "novo olhar", sobre aquilo que já temos como verdadeiro e certo e sobre os pressupostos conceituais e valorativos que condicionam nosso pensar e agir dentro de uma sociedade profundamente desigual em todos os níveis.

Nesse sentido, a compreensão de que a gestão dos currículos escolares no Brasil deve levar em conta o campo do multiculturalismo, isto é, que é importante pensar os currículos sob a égide da diversidade cultural, só amplia o leque de ação educativa para a construção da emancipação humana. Nessa mesma esteira, a estratégia de se buscar a conscientização a respeito do combate ao racismo e à discriminação, dentro do ambiente escolar, colabora para o entendimento e a afirmação desse espaço como privilegiado de educação 
atenta às diferenças, à alteridade, ao “outro", diferenças que, muitas vezes, se fazem sutis.

Segundo Moreira e Candau:

preconceitos e diferentes formas de discriminação estão presentes no cotidiano escolar e precisam ser problematizados, desvelados, desnaturalizados. Caso contrário, a escola estará a serviço da reprodução de padrões de conduta reforçadores dos processos discriminadores presentes na sociedade (MOREIRA; CANDAU, 2003, p. 164).

Algumas indicações de abordagens face aos desafios apresentados mostram que tal relação entre escola e culturas é, em si mesma, complexa, uma vez que o contexto sociohistórico em que se efetiva acaba por exigir uma releitura de paradigmas e de visões/verdades que se têm sobre a educação.

\section{À guisa de conclusão}

Faz-se necessário questionar essa realidade, buscando construir uma escola e sociedade democráticas, cujo locus passe pela formação docente ampla, crítica e consciente dos desafios imperativos da sociedade globalizada, excludente e, ao mesmo tempo, multicultural em que vivemos. Entendemos que é através de uma visão de respeito à alteridade e aos vários grupos sociais e étnicos existentes que será plausível a construção de um "projeto políticopedagógico" 5 que ateste o papel da escola como um dos alicerces fundantes de uma sociedade realmente moderna, democrática e, talvez, menos injusta.

Enfim, para além do discurso, importante é nos convencermos da urgência de uma releitura de nossas práticas e currículos escolares, de maneira que assumamos uma postura ética alicerçada sobre a crítica epistemológica rigorosa e a autorreflexão. $O$ que não podemos mais - educadores e instituições de ensino - é nos furtar do compromisso, essencialmente pelo "lugar social" que ocupamos, de desvendar os mecanismos que impedem o ser humano de ser livre, de ser emancipado, portanto, de pensar a educação emancipatória.

\footnotetext{
${ }^{5}$ Ao escolhermos um projeto pedagógico estamos, necessariamente, escolhendo uma orientação construtiva e curricular política, ou seja, que tem a imperativa função social de transformação da realidade e da sociedade para melhor. Portanto, todo projeto pedagógico tem em si uma essência política, posto que é transformadora. É preciso ter claro "que professores [e alunos] se pretende formar para atuarem no contexto da sociedade brasileira contemporânea", uma vez que "os professores são profissionais essenciais nos processos de mudança das sociedades” (PIMENTA; ANASTASIOU, 2002, p. II). Não é exagero afirmar que quando escolhemos um modelo de atuação e prática curricular, ao mesmo tempo estamos optando por um modelo de escola e, principalmente, de sociedade e de homem que queremos.
} 


\section{Referências}

ADORNO, T. W. Educação e Emancipação. Rio de Janeiro: Paz e Terra, 1995.

ARANHA, M. L. A.; PIRES, M. H. P. Filosofando: introdução à filosofia. 2. ed. São Paulo: Moderna, 1993.

HALL, S. A centralidade da cultura: notas sobre as revoluções de nosso tempo. Educação \& Realidade, v. 22, n. 2, p. I5-46, 1997.

MOREIRA, A. F. B.; CANDAU, V. M. Educação escolar e cultura (s): construindo caminhos. Revista Brasileira de Educação, Rio de Janeiro, n. 23, p. I56-I68, maio/ago. 2003.

ORTIZ, R. Mundialização e cultura. São Paulo: Brasiliense, 1994.

PIMENTA, S. G.; ANASTASIOU, L. G. C. Docência no ensino superior. São Paulo: Cortez, 2002. v. I.

SEN, A. O racha do multiculturalismo. Folha de S. Paulo, I 7 set. 2006. Suplemento Mais, p. 3. 


\section{A reflection concerning the teaching construction based on a fair syllabus}

\section{Abstract}

As regards that a complex process of changing minds, values and attitudes as for the personal and cultural relations in a world where the capital and production globalization idea determines new ways and positions to be, to think and to act, we propose a discussion about the teaching and syllabus building as issues that reflect this process of breaking paradigms. We search to confirm the central position of the culture in an emancipated education building based on respect and companionship with the alterity, in way that we can think about the education and the school we want, in a society where the values of justice and autonomy of thought deeply walk relativized.

Keywords: culture; education; emancipation; syllabus. 